J. Lake Sci. (湖泊科学), 2012, 24(6): 923-931

http: //www. jlakes.org. E-mail : jlakes@niglas.ac.cn

(c) 2012 by Journal of Lake Sciences

\title{
南水北调东线调度对南四湖水质的影响
}

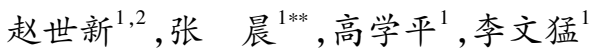 \\ ( 1 : 天津大学水利工程仿真与安全国家重点实验室, 天津 300072) \\ ( 2 : 国务院南水北调工程建设委员会办公室,北京 100038)
}

\begin{abstract}
摘 要: 南水北调东线一期工程 2013 年通水, 必将对南四湖水质产生重大影响. 借鉴既有成功理论方法, 建立南四湖三 维水力调配和水质模型,并经实测值验证. 利用该三维模型, 模拟南水北调东线一个完整调水期中的南四湖常规、干旱调 水工况调度运行过程, 分析南四湖上级湖、下级湖的水力和水质变化规律, 提出加强和改善南水北调东线调度管理的措 施和建议,既可充分发挥南水北调工程效益, 又可改善南四湖水质.
\end{abstract}

关键词: 水质; 调度;南水北调;南四湖

\section{The impact of the operation of Eastern Route Project of the South-to-North Water Diver- sion Project on water quality in Lake Nansi}

\author{
ZHAO Shixin ${ }^{1,2}$, ZHANG Chen ${ }^{1}$, GAO Xueping ${ }^{1} \&$ LI Wenmeng ${ }^{1}$ \\ (1: State Key Laboratory of Hydraulic Engineering Simulation and Safety, Tianjin University, Tianjin 300072, P. R. China) \\ (2: The Office of the South-to-North Water Diversion Project Construction Committee of the State Council, Beijing 100038, \\ P. R. China)
}

Abstract: Lake Nansi consists of four lakes: the Nanyang, Dushan, Zhaoyang and Weishan Lake. It is a lake in the line of the Eastern Route Project (ERP) of the South-to-North Water Diversion Project (NSBD). After the project supply water in 2013, the water quality of Lake Nansi will be affected significantly. Based on the existing theories and methods, a three-dimensional hydraulic control and water quality model of the lake is presented. The model is developed under the Environmental Fluid Dynamics Code (EFDC) model. It was calibrated and verified to hydrodynamic and water quality data, using two sets of observed data from October 1 to December 31, 2006 and January 1 to June 30, 2007, respectively. The observed data including water surface elevation, water temperature, chemical oxygen demand, dissolved oxygen and ammonia nitrogen from five stations is used as forcing for simulations. The model results show that temporal and spatial patterns for hydrodynamic and water quality components are consistent with observed data in the reservoir. Because the direction of the water supply and natural flow is converse, the Lake Nansi is divided into the upper-lake and the lower-lake by Erji dam in the Lake Zhaoyang. Two scenarios of whole supplying water term of the lake were simulated using the model. By the analysis of the variations of the hydraulic control and water quality of the upper-lake and lower-lake, This paper proposed three advices of the ERP operation, which can help the project to give full benefits and improve the water quality.

Keywords: Water quality; operation; South-to-North Water Diversion Project; Lake Nansi

南水北调工程是我国战略性基础设施,规划从长江下游、中游和上游调水,到 2050 年年总调水量为 $448 \times$ $10^{8} \mathrm{~m}^{3}$, 其中东线为 $148 \times 10^{8} \mathrm{~m}^{3}$, 中线为 $130 \times 10^{8} \mathrm{~m}^{3}$, 西线为 $170 \times 10^{8} \mathrm{~m}^{3}$. 目前正在建设东、中线一期工程, 总 长近 $3000 \mathrm{~km}$, 总投资约 2600 亿元, 东线设计年调水量为 $88 \times 10^{8} \mathrm{~m}^{3}$, 中线设计年调水量为 $95 \times 10^{8} \mathrm{~m}^{3}$. 按照建

* 国家 “十一五” 科技支撑计划项目(2006BAB04A15)、国家自然科学基金项目 (50909070) 和国家自然科学基金创新 研究群体科学基金项目 (51021004) 联合资助. 2012-01-17 收稿;2012-04-15 收修改稿. 赵世新, 男,1971 年生, 博士研究生; E-mail : shxzhao@ mwr. gov. cn.

** 通信作者;E-mail:emil@ tju. edu.cn. 
设目标, 东线即将于 2013 年通水. 南四湖是南水北调东线工程的在线实时调蓄水库, 据苏鲁省际, 人湖河流多, 调水流向与天然流向相反, 水力条件和水质条件复杂. 只有保证南四湖水质, 才能发挥南水北调工程效益.

借鉴季振刚等 ${ }^{[1]}$ 应用环境流体动力学模型 (Environmental Fluid Dynamics Code, EFDC) 对河流、湖泊、水 库、河口等水域的水环境模拟, 高学平和张晨等 ${ }^{[2-3]}$ 对于桥水库、北大港水库的三维水质模拟及预测, 何少苓 等 ${ }^{[4]}$ 利用水域水动力特性的潜力提高水域的纳污和自净能力, 傅春等 ${ }^{[5]}$ 以复杂理论为框架建立鄱阳湖综合 承载能力优化模型, 赖锡军等 ${ }^{[6]}$ 采用二维水动力和水质耦合方法对鄱阳湖的数值模拟,谢兴勇等 ${ }^{[7]}$ 模拟 “引 江济巢” 的调度方式等研究方法和成果, 周小平等 ${ }^{[8]}$ 对 “引江济太” 工程改善太湖水质等探索实践. 本文建立 三维水力调配和水质模型, 模拟南水北调东线调水期南四湖的调度运行过程, 分析水力、水质变化规律, 提 出南四湖调度运行的意见和建议.

\section{1 南四湖概况}

南四湖是南阳湖、独山湖、昭阳湖和微山湖四个相连湖泊的总称, 是华北地区最大的湖泊, 位于山东省 西南部, 自北向南流动, 全湖面积 $1266 \mathrm{~km}^{2}$, 湖泊容积 $16.06 \times 10^{8} \mathrm{~m}^{3}$. 南四湖总流域面积 $317 \times 10^{4} \mathrm{hm}^{2}$; 人湖 河流 53 条, 流域面积 $10 \times 10^{4} \mathrm{hm}^{2}$ 以上者 9 条, 在 $1 \times 10^{4} \sim 10 \times 10^{4} \mathrm{hm}^{2}$ 之间有 15 条, 其余均在 $1 \times 10^{4} \mathrm{hm}^{2}$ 以 下; 出湖河流 2 条, 即韩庄运河和不牢河; 平均水深约 $2 \mathrm{~m}$; 湖区共有大小取水口 250 多个; 昭阳湖中所建二级 坝将南四湖分为上、下级湖 ${ }^{[9-10]}$. 韩庄㬌站和萄家坝㬌站是南水北调东线工程的第 9 级原站, 二级坝原站、长沟原站 分别为第 $10 、 11$ 级葲站,通过三级泵站由南向北调水至东平湖. 南四湖水系及调水工程示意见图 1.

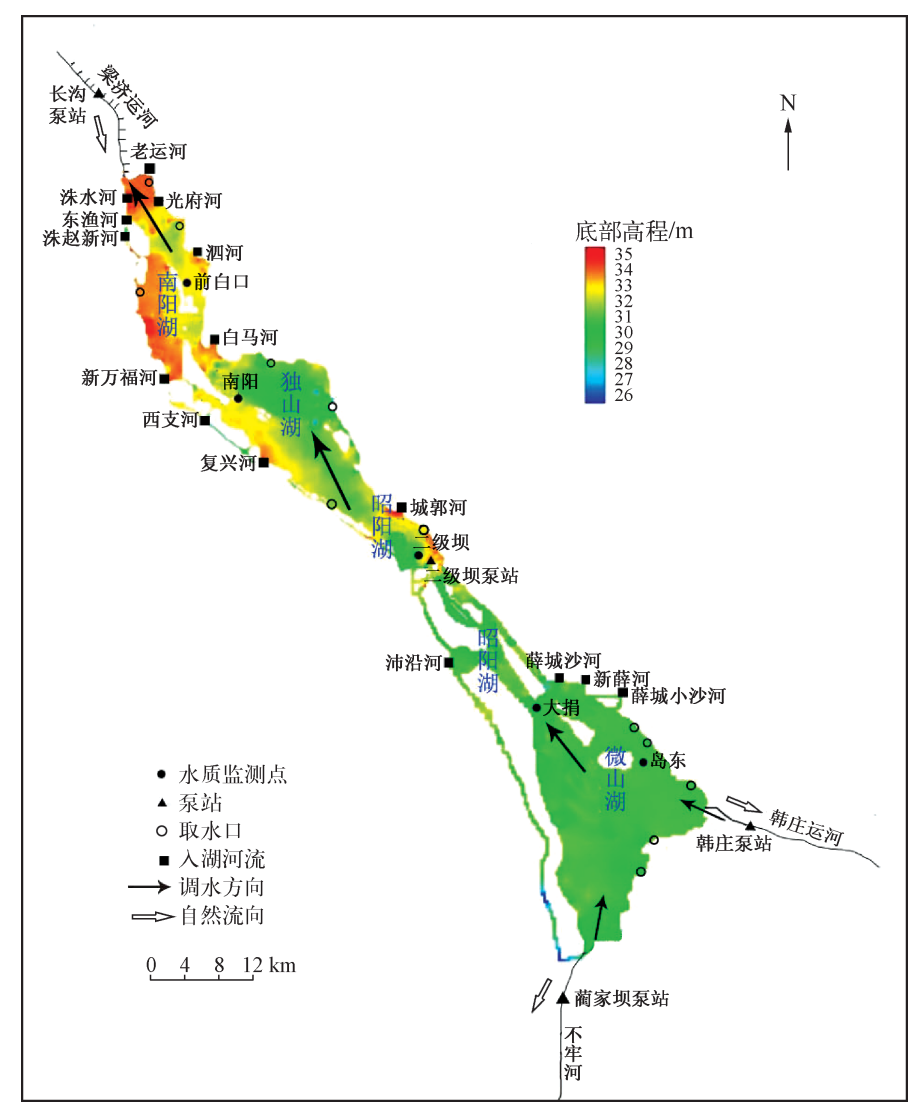

图 1 南四湖水系及调水工程示意图

Fig. 1 The water system and the water diversion projects in Lake Nansi 


\section{2 计算模型}

由于南四湖人湖河流和取水口众多, 水系复杂, 为了较精确地模拟支流汇流对湖区水质的影响, 依据连 续性方程、动量方程、自由表面方程、状态方程和水质浓度输运方程, 建立南四湖三维水力调配和水质模型, 耦 合计算水动力和水质. 水动力计算参量包括水位、流量和流速; 水质计算参量包括水温、 $\mathrm{pH、}$ 、溶解氧、氯化物、化 学需氧量、高锰酸盐指数、铵态氮、亚硝酸盐、总氮、总磷、硅、粪大肠杆菌和氟化物等.

\section{1 计算方程}

连续性方程为:

$$
\frac{\partial(m \zeta)}{\partial t}+\frac{\partial\left(m_{x} H u\right)}{\partial x}+\frac{\partial\left(m_{x} H v\right)}{\partial y}+\frac{\partial(m w)}{\partial z}=Q_{H}
$$

动量方程为:

$$
\begin{gathered}
\frac{\partial(m H u)}{\partial t}+\frac{\partial\left(m_{y} H u u\right)}{\partial x}+\frac{\partial\left(m_{x} H v u\right)}{\partial y}+\frac{\partial(m w u)}{\partial z}-\left(m f+v \frac{\partial m_{y}}{\partial x}-u \frac{\partial m_{x}}{\partial y}\right) H v \\
=-m_{y} H \frac{\partial(g \zeta+p)}{\partial x}-m_{y}\left(\frac{\partial h}{\partial x}-z \frac{\partial H}{\partial x}\right) \frac{\partial p}{\partial z}+\frac{\partial}{\partial z}\left(m \frac{1}{H} A_{v} \frac{\partial u}{\partial z}\right)+Q_{u} \\
\frac{\partial(m H v)}{\partial t}+\frac{\partial\left(m_{y} H u v\right)}{\partial x}+\frac{\partial\left(m_{x} H v v\right)}{\partial y}+\frac{\partial(m w v)}{\partial z}+\left(m f+v \frac{\partial m_{y}}{\partial x}-u \frac{\partial m_{x}}{\partial y}\right) H u \\
=-m_{x} H \frac{\partial(g \zeta+p)}{\partial y}-m_{x}\left(\frac{\partial h}{\partial y}-z \frac{\partial H}{\partial y}\right) \frac{\partial p}{\partial z}+\frac{\partial}{\partial z}\left(m \frac{1}{H} A_{v} \frac{\partial v}{\partial z}\right)+Q_{v}
\end{gathered}
$$

状态方程为:

$$
\rho=\rho(p, S, T)
$$

浓度输运方程为:

$$
\frac{\partial(m H \Phi)}{\partial t}+\frac{\partial\left(m_{y} H u \Phi\right)}{\partial x}+\frac{\partial\left(m_{x} H v \Phi\right)}{\partial y}+\frac{\partial(m w \Phi)}{\partial z}=\frac{\partial}{\partial z}\left(m \frac{1}{H} A_{b} \frac{\partial \Phi}{\partial z}\right)+Q_{\Phi}
$$

式中, $u$ 和 $v$ 是曲线正交坐标系下 $x$ 和 $y$ 方向的流速分量 $(\mathrm{m} / \mathrm{s}) ; m_{x} 、 m_{y} 、 m$ 是 Jacobian 曲线正交坐标转换系 数, $m=m_{x} m_{y} \cdot Q_{H}$ 代表降雨、蒸发、地下水相互作用、取水或点源和非点源人流 $(\mathrm{m} / \mathrm{s}) ; p$ 为相对静水压力 $\left((\mathrm{kg} \cdot \mathrm{m}) / \mathrm{s}^{2}\right), p=\rho_{0} g H(1-z) ; f$ 为柯氏力参量 $\left(\mathrm{s}^{-1}\right) ; A_{v}$ 为垂向紊流黏滞系数 $\left(\mathrm{m}^{2} / \mathrm{s}\right) ; Q_{u}$ 和 $Q_{v}$ 为动量源 汇项 $\left(\mathrm{m}^{2} / \mathrm{s}^{2}\right) ; \rho$ 为密度 $\left(\mathrm{kg} / \mathrm{m}^{3}\right)$; 浓度输运方程中 $A_{b}$ 为垂向紊动扩散系数 $\left(\mathrm{m}^{2} / \mathrm{s}\right) ; Q_{\phi}$ 为源汇项 $\left(\mathrm{g} /\left(\mathrm{m}^{2} \cdot \mathrm{s}\right)\right)$; $\Phi$ 为某种水质组分的浓度 $(\mathrm{mg} / \mathrm{L})^{[11-13]}$. 垂向紊流黏滞系数 $A_{v}$ 和垂向紊动扩散系数 $A_{b}$ 通过求解紊动能量 $q^{2}$ 和紊动尺度 $l$ 的紊动方程确定, $q^{2}$ 和 $l$ 的紊动方程详见参考文献 [12].

\section{2 计算方法}

采用空间交错网格, 网格单元数为 10516 , 其中上级湖为 5535 , 下级湖为 4981 , 网格大小为 $300 \mathrm{~m} \times 300 \mathrm{~m}$, 垂向分 2 层计算. 应用内-外模式分离法求解连续性方程和动量方程, 半隐式三层时间格式求解外模式, 周 期性的两层时间格式修正, 求得自由表面水位变化. 应用连续超松驰格式迭代求解水位变化的垂向平均 速度场. 联合水平速度分量和垂向剪力项, 应用分步格式求解内模式, 隐式求解垂向剪力项, 显式求解 其他项 ${ }^{[14]}$. 紊动强度、紊动长度尺度等的输运方程求解应用分步法, 隐式求解垂向扩散项, 显式求解对 流项.

\section{3 模型验证}

以主要影响南四湖水质的溶解氧 $(\mathrm{DO})$ 、化学需氧量 $(\mathrm{COD})$ 、铵态氮 $\left(\mathrm{NH}_{4}^{+}-\mathrm{N}\right)$ 为模拟指标, 进行水动力、 水质模拟,选取南四湖自然流态 2006 年 10 月 1 日至 2007 年 6 月 30 日,共 $273 \mathrm{~d}$ 的实测资料进行模型验证. 其中,根据 2006 年 10-12 月的数据进行模型率定, 2007 年 1-6 月的数据进行验证.

上级湖初始水位为 $34.2 \mathrm{~m}$, 下级湖初始水位为 $33.0 \mathrm{~m}$, 水质初始浓度为 2006 年 10 月的实测浓度值, 详 
表 1 水质监测点实测浓度 $(2006$ 年 10 月)

Tab. 1 The observed data in water quality monitoring sites in Oct., 2006

\begin{tabular}{lcccc}
\hline 监测断面 & $\mathrm{pH}$ & $\begin{array}{c}\mathrm{COD} / \\
(\mathrm{mg} / \mathrm{L})\end{array}$ & $\begin{array}{c}\mathrm{NH}_{4}^{+}-\mathrm{N} / \\
(\mathrm{mg} / \mathrm{L})\end{array}$ & $\begin{array}{c}\mathrm{DO} / \\
(\mathrm{mg} / \mathrm{L})\end{array}$ \\
\hline 前白口 & 7.8 & 36.0 & 2.2 & 6.8 \\
南阳 & 7.9 & 27.0 & 1.8 & 7.4 \\
二级坝 & 7.9 & 33.5 & 1.9 & 7.6 \\
大捐 & 7.8 & 26.8 & 2.0 & 8.0 \\
岛东 & 7.9 & 23.2 & 2.0 & 8.2 \\
\hline
\end{tabular}

见表 1 . 水力边界条件, 梁济运河人流流量为 $40 \mathrm{~m}^{3} / \mathrm{s}$, 二级 坝流量为 $35 \mathrm{~m}^{3} / \mathrm{s}$, 韩庄运河、不牢河出流流量分别为 $20 、 10$ $\mathrm{m}^{3} / \mathrm{s}$. 水质边界条件, 梁济运河人流水质指标时序浓度值 根据实测资料给定. 考虑泗河、东渔河、城郭河、新薛河等 15 条人湖河流的污染负荷对南四湖水质的影响.

通过比较水位模拟值和实测值, 对水动力进行了验证, 龯率率定为 $0.020 \sim 0.025$, 水位相对误差为 $3 \%$. 由于文章 篇幅有限, 文中未详细阐述. 将前白口、南阳、二级坝、大 捐、岛东 5 个水质监测点处的 $\mathrm{COD} 、 \mathrm{NH}_{4}^{+}-\mathrm{N}$ 的模拟值和 实测值进行对比, 结果见表 2 , 误差未超过 $30 \%$, 模拟精 度较好.

表 2 南四湖各水质监测点 $\mathrm{COD}$ 和 $\mathrm{NH}_{4}^{+}-\mathrm{N}$ 浓度模拟值与实测值比较*

Tab. 2 Comparison between the simulated and observed data of COD and $\mathrm{NH}_{4}^{+}-\mathrm{N}$ in water quality monitoring sites of Lake Nansi

\begin{tabular}{|c|c|c|c|c|c|c|c|c|c|c|c|c|c|c|c|}
\hline \multirow{3}{*}{ 时间/d } & \multicolumn{15}{|c|}{ COD } \\
\hline & \multicolumn{3}{|c|}{ 前白口 } & \multicolumn{3}{|c|}{ 南阳 } & \multicolumn{3}{|c|}{ 二级坝 } & \multicolumn{3}{|c|}{ 大捐 } & \multicolumn{3}{|c|}{ 岛东 } \\
\hline & Sim. & Obs. & Err. & Sim. & Obs. & Err. & Sim. & Obs. & Err. & Sim. & Obs. & Err. & Sim. & Obs. & Err. \\
\hline 30 & & & & & & & 24.8 & 25.0 & 0.8 & 25.7 & 26.8 & 4.1 & 22.5 & 23.0 & 2.2 \\
\hline 60 & 34.5 & 34.0 & 1.5 & 31.3 & 32.0 & 2.2 & 29.6 & 22.8 & 29.8 & 25.3 & 25.0 & 1.2 & 21.2 & 24.0 & 11.7 \\
\hline 90 & & & & & & & 27.8 & 24.0 & 15.8 & 25.1 & 22.0 & 14.1 & 21.6 & 20.0 & 8.0 \\
\hline 120 & & & & & & & 28.1 & 26.0 & 8.1 & 25.2 & 23.0 & 9.6 & 22.3 & 22.0 & 1.4 \\
\hline 150 & & & & & & & 28.2 & 25.7 & 9.7 & 24.9 & 23.0 & 8.3 & 22.3 & 22.0 & 1.4 \\
\hline 180 & 35.4 & 34.3 & 3.2 & 36.4 & 38.0 & 4.2 & 26.3 & 22.0 & 19.6 & 25.1 & 23.0 & 9.1 & 22.5 & 21.3 & 5.6 \\
\hline 210 & 35.1 & 36.2 & 3.0 & & & & & & & & & & & & \\
\hline 240 & 35.2 & 36.0 & 2.2 & 34.2 & 35.0 & 2.3 & 31.2 & 28.5 & 9.5 & & & & & & \\
\hline \multirow[t]{2}{*}{270} & & & & 35.3 & 34.0 & 3.8 & & & & 24.8 & 22.5 & 10.2 & 19.5 & 19.4 & 0.5 \\
\hline & \multicolumn{15}{|c|}{$\mathrm{NH}_{4}^{+}-\mathrm{N}$} \\
\hline \multirow[t]{2}{*}{ 时间/d } & \multicolumn{3}{|c|}{ 前白口 } & \multicolumn{3}{|c|}{ 南阳 } & \multicolumn{3}{|c|}{ 二级坝 } & \multicolumn{3}{|c|}{ 大捐 } & \multicolumn{3}{|c|}{ 岛东 } \\
\hline & Sim. & Obs. & Err. & Sim. & Obs. & Err. & Sim. & Obs. & Err. & Sim. & Obs. & Err. & Sim. & Obs. & Err. \\
\hline 30 & & & & & & & 1.6 & 2.0 & 20.0 & 2.2 & 2.0 & 10.0 & & & \\
\hline 60 & 2.4 & 2.5 & 4.0 & & & & 2.5 & 2.0 & 25.0 & 2.1 & 2.0 & 5.0 & 2.5 & 2.0 & 25.0 \\
\hline 90 & 2.3 & 2.2 & 4.5 & & & & & & & 2.0 & 1.8 & 11.1 & & & \\
\hline 120 & 2.6 & 2.3 & 13.0 & & & & & & & 2.1 & 2.0 & 5.0 & 2.1 & 2.0 & 5.0 \\
\hline 150 & 2.4 & 2.1 & 14.3 & & & & 2.3 & 1.8 & 27.8 & 1.9 & 2.0 & 5.0 & 2.0 & 2.0 & 0.0 \\
\hline 180 & 2.1 & 2.0 & 5.0 & 2.4 & 2.0 & 20.0 & & & & & & & & & \\
\hline 210 & & & & & & & 2.4 & 1.9 & 26.3 & 2 & 2.0 & 0.0 & 2.1 & 2.0 & 5.0 \\
\hline 240 & 2.6 & 2.3 & 13.0 & 2.3 & 2.3 & 0 & 1.8 & 2.5 & 28.0 & 1.9 & 2.2 & 13.6 & 2.2 & 2.4 & 8.3 \\
\hline 270 & 2.4 & 3.0 & 20.0 & 2.4 & 1.9 & 26.3 & & & & 1.8 & 2.5 & 28.0 & 2.5 & 2.0 & 25.0 \\
\hline
\end{tabular}

* Sim. 表示模拟值 $(\mathrm{mg} / \mathrm{L})$; Obs. 表示实测值 $(\mathrm{mg} / \mathrm{L})$; Err. 表示相对误差 (\%).

\section{3 调水期水力水质变化过程分析}

模拟南四湖一个完整调水时段 $(1 \mathrm{a}, 365 \mathrm{~d})$, 计算条件包括地形, 初始水位, 水体 DO、 $\mathrm{COD} 、 \mathrm{NH}_{4}^{+}-\mathrm{N}$ 浓度 分布, 东线调水以及湖区主要支流的人流和出流流量, 污染负荷等. 由于南四湖被二级坝分割成上级湖和下 
级湖, 水流条件不连续, 通过二级坝泵站将下级湖水抽至上级湖, 故先模拟调水期下级湖水质变化情况, 得 到下级湖出水口 (二级坝百站附近) 水质的变化规律,再进行上级湖水质模拟分析.

调水期间下级湖初始水位为 $33.0 \mathrm{~m}$, 上级湖水位为 $34.2 \mathrm{~m}$; 水质初始浓度采用 2006 年 10 月的实测浓 度值. 方案一: 常规调水工况, 水力边界条件, 韩庄㫤站和萄家坝泉站抽水人下级湖, 流量分别为 $125 \mathrm{~m}^{3} / \mathrm{s}$ 和 $75 \mathrm{~m}^{3} / \mathrm{s}$; 二级坝原站抽水人上级湖, 流量为 $125 \mathrm{~m}^{3} / \mathrm{s}$; 长沟原站抽水出上级湖, 流量为 $100 \mathrm{~m}^{3} / \mathrm{s}$. 水质边界条 件, 下级湖两个人水口的水质相同, $\mathrm{NH}_{4}^{+}-\mathrm{N}$ 浓度为 $0.8 \mathrm{mg} / \mathrm{L}, \mathrm{COD}$ 浓度为 $16.0 \mathrm{mg} / \mathrm{L}, \mathrm{DO}$ 浓度为 $8.0 \mathrm{mg} / \mathrm{L}$; 下级湖二级坝原站附近的湖水作为上级湖的人流水质条件. 方案二: 特殊干旱年份调水工况, 仅韩庄原站抽 水人下级湖, 流量为 $80 \mathrm{~m}^{3} / \mathrm{s}$; 二级坝洜站抽水人上级湖, 流量为 $80 \mathrm{~m}^{3} / \mathrm{s}$; 长沟原站抽水出上级湖, 流量为 $70 \mathrm{~m}^{3} / \mathrm{s}$, 水质条件与方案一相同.

为更加接近实际, 模拟中除考虑蒸发、降雨、地下水渗漏外, 还考虑人湖河流水量及周边地区灌溉用水、 工业用水、生活用水等, 使调水期内水量达到平衡; 考虑泗河、东渔河、城郭河、新薛河等 15 条人湖河流的污 染负荷对南四湖水质的影响.

\section{1 下级湖}

3.1 .1 水力变化分析 方案一:下级湖两个人水口附近的流速较大, 韩庄葲站人水口的湖区流速达到 $16.0 \sim$ $17.0 \mathrm{~cm} / \mathrm{s}$; 㖪家坝人水口附近的湖区流速为 $3.0 \sim 4.0 \mathrm{~cm} / \mathrm{s}$. 微山湖南半湖区流速较平缓, 为 $0.5 \sim 1.0 \mathrm{~cm} / \mathrm{s}$; 北半湖区由于微山岛的存在, 流速高于南半湖区. 微山岛东侧湖区面积小、流量大, 流速为 $1.3 \sim 1.5 \mathrm{~cm} / \mathrm{s}$; 西侧流速为 $0.8 \sim 1.2 \mathrm{~cm} / \mathrm{s}$. 昭阳湖与微山湖相连处流速较大, 该湖区分成两条河流, 西侧河流人口处流速 为 $4.6 \sim 6.8 \mathrm{~cm} / \mathrm{s}$, 河流流速可以达到 $7.5 \sim 8.2 \mathrm{~cm} / \mathrm{s}$; 东侧河流人口处流速为 $1.4 \sim 2.3 \mathrm{~cm} / \mathrm{s}$, 河流流速为 $3.2 \sim 6.8 \mathrm{~cm} / \mathrm{s}$; 两条河流中间相交处流速为 $3.3 \sim 4.2 \mathrm{~cm} / \mathrm{s}$. 二级坝附近的湖区流速较大, 达到 $15.0 \mathrm{~cm} / \mathrm{s}$ 左右; 最大流速出现在二级坝百站进水口附近, 达到 $53.0 \mathrm{~cm} / \mathrm{s}$. 下级湖在调水期间湖区流场未出现大范围 的环流现象, 湖水流态平稳, 下级湖调水第 $90 \mathrm{~d}$ 方案一流场见图 $2 \mathrm{a}$.

方案二: 特殊干旱年份调水工况下仅韩庄原站抽水, 人湖水流成三个流向: 其中两股水流分别流向微山岛 东西两侧, 另有一股流向西南的萄家坝泉站方向. 由于调水流量减小, 湖区流速较方案一小 $0.3 \sim 7.8 \mathrm{~cm} / \mathrm{s}$, 二级坝原站进水口流速较方案一小 $23.0 \mathrm{~cm} / \mathrm{s}$. 湖区流场未出现大范围的环流现象, 湖水流态平稳, 下级湖 调水第 $90 \mathrm{~d}$ 方案二流场见图 $2 \mathrm{~b}$.

3.1 .2 水质变化分析 方案一: 在调水后 $90 \mathrm{~d}$ 内, 微山湖西部部分湖区 DO 浓度在 $3.0 \sim 5.6 \mathrm{mg} / \mathrm{L}$ 左右. 由 于韩庄原站的流量大于萄家坝原站, 湖区西部 DO 浓度低于东部. 在第 $90 \sim 210 \mathrm{~d}$ 之间, 随着湖水更新, COD 浓度和水温不断降低, 下级湖 DO 含量不断增高, 达到 $8.0 \sim 10.0 \mathrm{mg} / \mathrm{L}$ 左右. 在第 $210 \mathrm{~d}$ 之后, 湖水温度回 升, 昭阳湖南部湖区 DO 浓度降到约 $4.5 \sim 6.0 \mathrm{mg} / \mathrm{L}$, 微山湖为 $6.0 \mathrm{mg} / \mathrm{L}$ 左右. 调水周期内, 下级湖大部分湖 区 DO 含量符合 III类水标准. 第 $270 \mathrm{~d}$ 时, DO 浓度分布见图 $3 \mathrm{a}$.

在调水初期, 微山湖湖水更新较快, 东部湖区 COD 浓度在约 $30 \mathrm{~d}$ 时间内由 $30.0 \mathrm{mg} / \mathrm{L}$ 下降至 $16.0 \mathrm{mg} / \mathrm{L}$, 西部湖区 COD 浓度在约 $35 \mathrm{~d}$ 时间内由 $30.0 \mathrm{mg} / \mathrm{L}$ 下降至 $17.0 \mathrm{mg} / \mathrm{L}$. 调水 $38 \mathrm{~d}$ 之后, 微山湖湖区湖水全部 完成更新, 东部湖区稳定在 $16.0 \mathrm{mg} / \mathrm{L}$, 西部湖区为 $17.0 \mathrm{mg} / \mathrm{L}$. 调水 $50 \mathrm{~d}$ 之后, 下级湖的昭阳湖湖区完成更 新, 由于受到下级湖东岸的新薛河、薛城沙河、薛城小沙河和西岸的沛沿河的污水排人影响, 河流入湖口附 近 COD 浓度较高. 第 $270 \mathrm{~d}$ 时, COD 浓度分布见图 $3 \mathrm{~b}$.

湖区东部的 $\mathrm{NH}_{4}^{+}-\mathrm{N}$ 浓度在约 $25 \mathrm{~d}$ 内由 $3.0 \mathrm{mg} / \mathrm{L}$ 下降至 $0.8 \mathrm{mg} / \mathrm{L}$, 湖区西部的 $\mathrm{NH}_{4}^{+}-\mathrm{N}$ 浓度在约 $36 \mathrm{~d}$ 时间内由 $3.0 \mathrm{mg} / \mathrm{L}$ 下降至 $1.0 \mathrm{mg} / \mathrm{L}$. 调水 $38 \mathrm{~d}$ 之后, 微山湖湖区湖水全部更新完成, 东部湖区 $\mathrm{NH}_{4}^{+}-\mathrm{N}$ 稳定 在 $0.8 \mathrm{mg} / \mathrm{L}$, 西部湖区为 $1.0 \mathrm{mg} / \mathrm{L}$. 调水 $50 \mathrm{~d}$ 之后, 昭阳湖湖区完成更新, 同样受支流汇人影响, 河流人湖 口附近 $\mathrm{NH}_{4}^{+}-\mathrm{N}$ 浓度较高. 第 $270 \mathrm{~d}$ 时, $\mathrm{NH}_{4}^{+}-\mathrm{N}$ 浓度分布见图 $3 \mathrm{c}$.

在调水开始阶段,湖区的原有湖水不断汇集到二级坝附近, 使该区 $\mathrm{COD}$ 和 $\mathrm{NH}_{4}^{+}-\mathrm{N}$ 浓度不断上升. 调水 $30 \mathrm{~d}$ 之后, 优质水到达该湖区, 其 $\mathrm{COD}$ 和 $\mathrm{NH}_{4}^{+}-\mathrm{N}$ 浓度开始下降; 调水 $60 \mathrm{~d}$ 之后, $\mathrm{COD}$ 稳定在 $16.0 \mathrm{mg} / \mathrm{L}$, $\mathrm{NH}_{4}^{+}-\mathrm{N}$ 浓度为 $1.0 \mathrm{mg} / \mathrm{L}$ 左右. $\mathrm{DO}$ 浓度变化规律受 $\mathrm{COD}$ 和 $\mathrm{NH}_{4}^{+}-\mathrm{N}$ 浓度、湖水温度影响较大. 二级坝葲站 $\mathrm{DO} 、 \mathrm{COD} 、 \mathrm{NH}_{4}^{+}-\mathrm{N}$ 浓度变化曲线见图 4.

方案二: 由于人下级湖流量从 $200 \mathrm{~m}^{3} / \mathrm{s}$ 减小至 $80 \mathrm{~m}^{3} / \mathrm{s}$, 污染物随流运动的物理作用降低, 更新时间也 


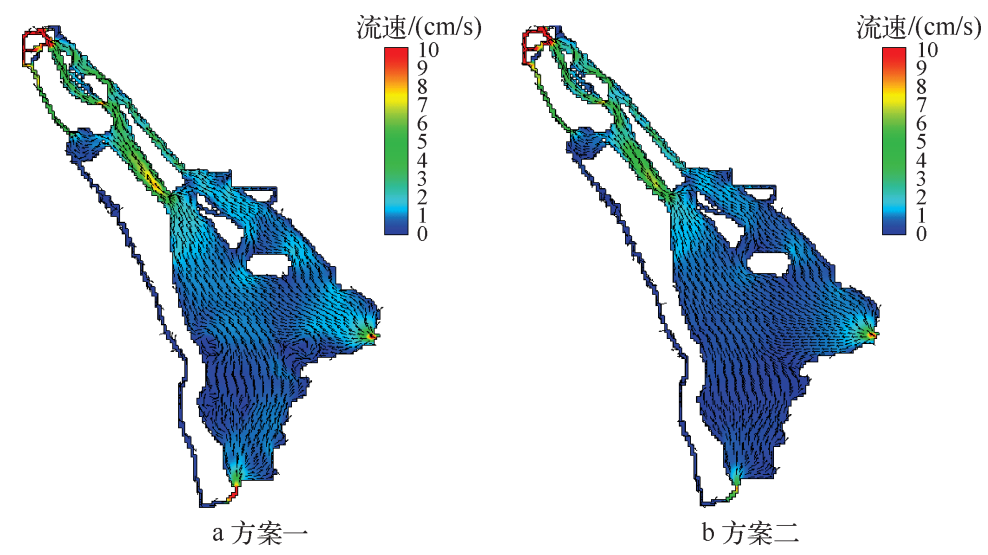

图 2 下级湖调水第 $90 \mathrm{~d}$ 流场分布

Fig. 2 Distribution of the flow field in the lower-lake on the 90th day
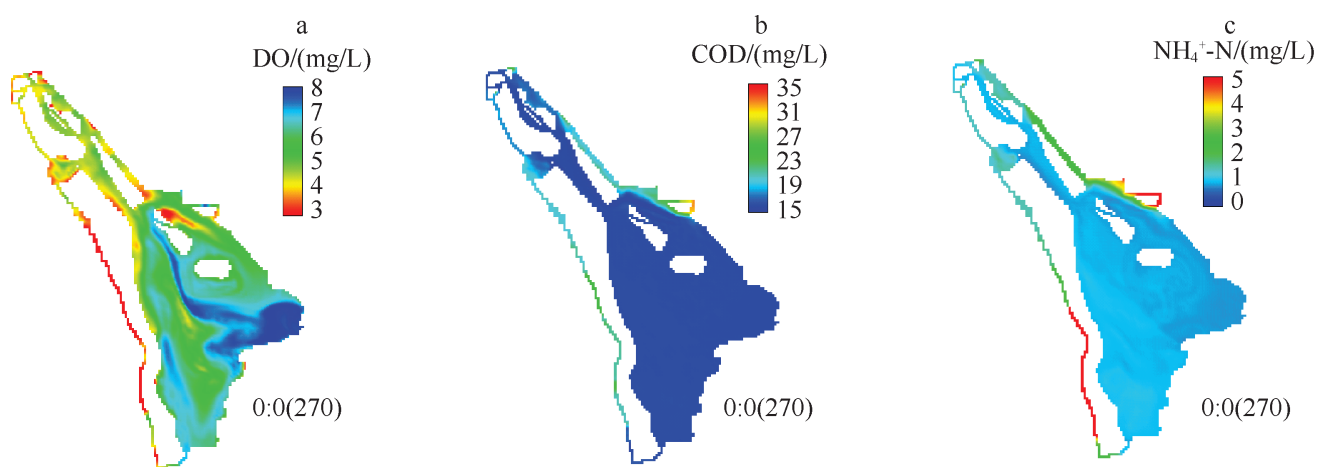

图 3 下级湖水质浓度分布 (第 $270 \mathrm{~d}$,方案一)

Fig. 3 Concentrations distribution of the water quality parameters in the lower-lake on the 270th day

随之增加, 调水 $90 \mathrm{~d}$ 之后下级湖的昭阳湖区才基本完成更新. 由于萄家坝原站不参与调水, 微山湖西部湖区 水体交换减弱, $\mathrm{COD}$ 浓度在约 $160 \mathrm{~d}$ 内由 $30.0 \mathrm{mg} / \mathrm{L}$ 下降至 $16.0 \mathrm{mg} / \mathrm{L} ; \mathrm{NH}_{4}^{+}-\mathrm{N}$ 浓度在约 $180 \mathrm{~d}$ 内由 $3.0 \mathrm{mg} / \mathrm{L}$ 下降至 $1.0 \mathrm{mg} / \mathrm{L}$. 稳定后, 下级湖各湖区浓度分布与方案一大致相同, 但受水力特性的影响, 二级坝原站附 近 $\mathrm{COD}$ 和 $\mathrm{NH}_{4}^{+}-\mathrm{N}$ 浓度较方案一分别高 $2.8 \mathrm{mg} / \mathrm{L}$ 和 $0.4 \mathrm{mg} / \mathrm{L}$ (图 4).

$$
\text { 一方案一 ……方案二 }
$$
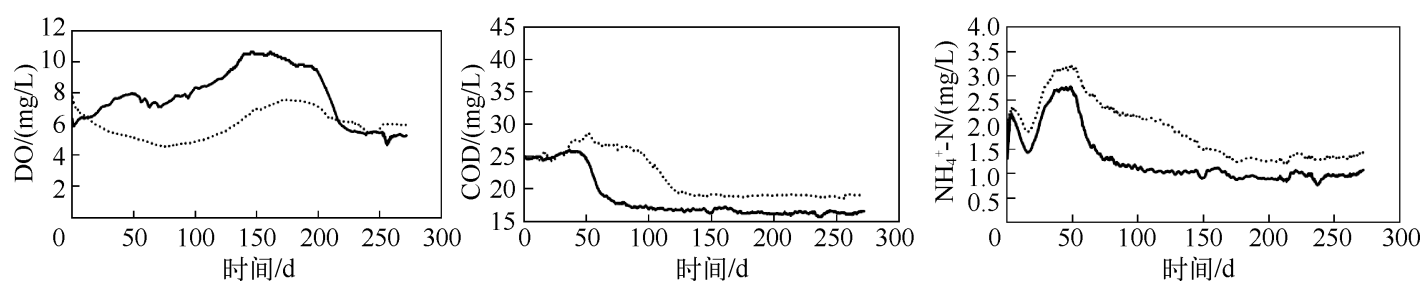

图 4 二级坝葲站水质浓度变化曲线

Fig. 4 Variations of the water quality parameters at the Erjiba pump site 


\section{2 上级湖}

3.2 .1 水力变化分析 方案一:上级湖昭阳湖部分湖区流速为 $0.8 \sim 1.8 \mathrm{~cm} / \mathrm{s}$, 距离人水口较近的湖区为 $1.7 \sim$ $2.8 \mathrm{~cm} / \mathrm{s}$; 独山湖与昭阳湖相接处的流速较小, 为 $0.8 \sim 1.2 \mathrm{~cm} / \mathrm{s}$; 独山湖南半湖区流速为 $2.0 \sim 4.5 \mathrm{~cm} / \mathrm{s}$, 北 半湖区流速较小, 仅为 $0.4 \sim 0.5 \mathrm{~cm} / \mathrm{s}$; 独山湖与南阳湖相接处的流速较大, 为 $2.0 \sim 3.5 \mathrm{~cm} / \mathrm{s}$; 南阳湖南半 湖区流速为 $0.6 \sim 0.8 \mathrm{~cm} / \mathrm{s}$, 北半湖区为 $1.0 \sim 2.0 \mathrm{~cm} / \mathrm{s}$; 南阳湖出水口附近的流速较大, 为 $5.0 \sim 6.5 \mathrm{~cm} / \mathrm{s}$. 上级湖在调水期间湖区流场未出现大范围的环流现象, 湖水流态平稳. 上级湖调水第 $90 \mathrm{~d}$ 方案一流场见 图 $5 \mathrm{a}$.

方案二: 特殊干早年份调水工况下人湖和出湖流量减小, 上级湖各湖区流速较方案一小 $0.2 \sim 3.5 \mathrm{~cm} / \mathrm{s}$, 湖区流场未出现大范围的环流现象, 湖水流态平稳,上级湖调水第 $90 \mathrm{~d}$ 方案二流场见图 $5 \mathrm{~b}$.

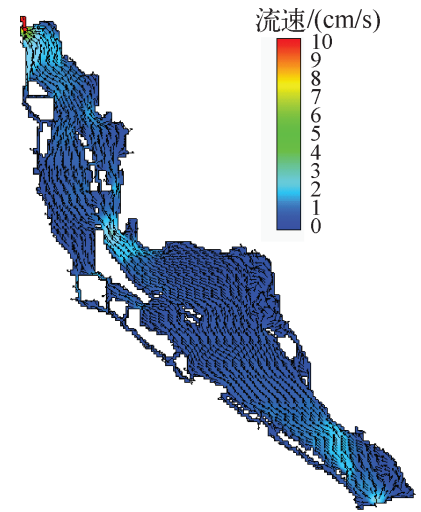

(a) 方案一

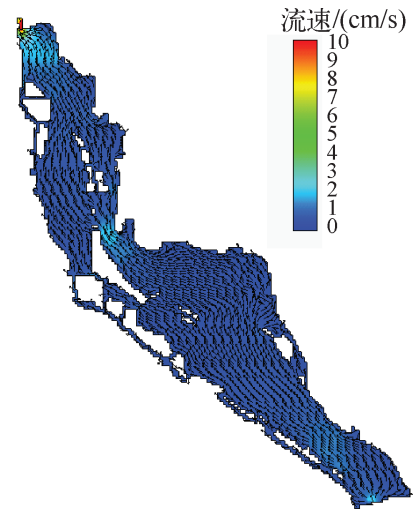

(b) 方案二

图 5 上级湖调水第 $90 \mathrm{~d}$ 流场分布

Fig. 5 Distribution of the flow field in the upper-lake on the 90th day

3.2 .2 水质变化分析 方案一:由于独山湖北端湖区不利于水体交换, 在调水开始至调水 $120 \mathrm{~d}, \mathrm{DO}$ 浓度低 于其他湖区, 其浓度在 $4.0 \mathrm{mg} / \mathrm{L}$ 左右, 其余湖区在 $5.0 \sim 8.0 \mathrm{mg} / \mathrm{L}$ 左右; 在调水 $150 \mathrm{~d}$ 之后, 随着湖水更新, 大部分湖区 DO 浓度达到 $9.0 \mathrm{mg} / \mathrm{L}$ 左右; $210 \mathrm{~d}$ 之后, 湖水温度回升, 湖区 DO 浓度又降低, 大部分湖区浓度 在 $7.3 \mathrm{mg} / \mathrm{L}$ 左右; 在调水周期内, 上级湖 DO 含量大部分时间符合 III 类水标准. $270 \mathrm{~d}$ 时, DO 浓度分布见 图 6a.
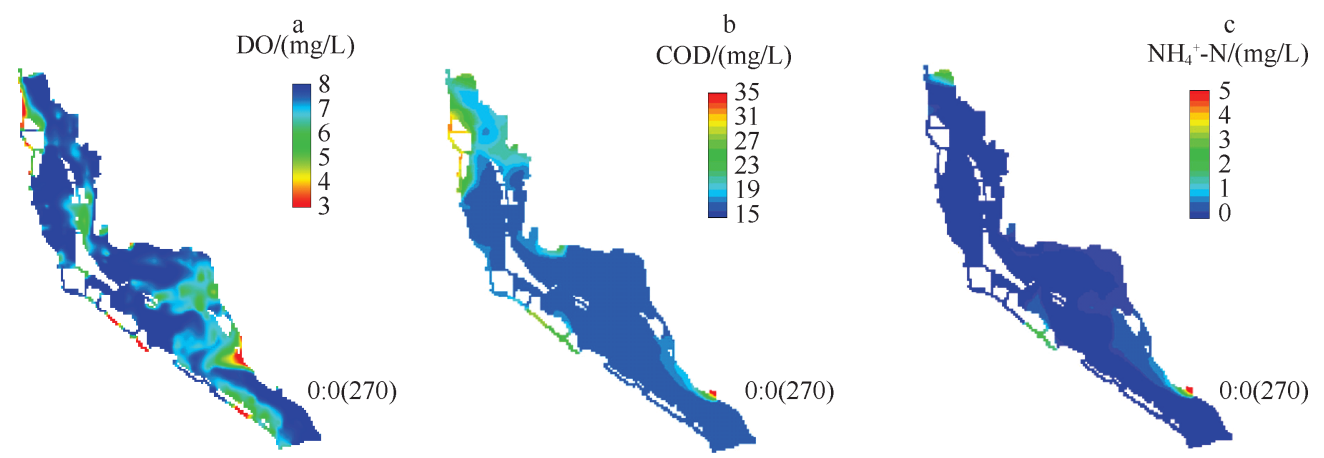

图 6 上级湖水质浓度分布 (第 $270 \mathrm{~d}$,方案一)

Fig. 6 Concentrations distribution of the water quality parameters in the upper-lake on the 270th day

随着调水开始, 湖水流向由自北向南转为自南向北, 下级湖不断通过二级坝百站向上级湖调水. 在调水 $43 \mathrm{~d}$ 之前, 调来之水主要为原下级湖储水, 水质较差; 调水 $43 \mathrm{~d}$ 之后, 来水水质逐渐好转; 调水 $60 \mathrm{~d}$ 之后, 上 级湖中的昭阳湖完成更新, COD 浓度由 $30.0 \mathrm{mg} / \mathrm{L}$ 下降至 $17.0 \mathrm{mg} / \mathrm{L}$; 调水 $115 \mathrm{~d}$ 之后独山湖大部分湖区完 
成更新, COD 浓度介于 $17.0 \sim 24.0 \mathrm{mg} / \mathrm{L}$ 之间. 调水 $160 \mathrm{~d}$ 后南阳湖大部分湖区完成更新, 水质趋于稳定, 南 阳湖北半湖区的水质受老运河、光府河、泗河、白马河、洙水河等支流的影响明显, 该区平均 COD 浓度为 $19.3 \mathrm{mg} / \mathrm{L}$, 高于上级湖其他湖区. 调水 $270 \mathrm{~d}$ 时, COD 浓度分布见图 $6 \mathrm{~b}$.

调水 $43 \mathrm{~d}$ 之后, 下级湖调人上级湖的湖水水质逐渐好转, $\mathrm{NH}_{4}^{+}-\mathrm{N}$ 浓度开始降低; 调水 $55 \mathrm{~d}$ 之后, 昭阳湖 $\mathrm{NH}_{4}^{+}-\mathrm{N}$ 浓度由 $3.0 \mathrm{mg} / \mathrm{L}$ 下降至 $1.0 \mathrm{mg} / \mathrm{L}$. 调水 $115 \mathrm{~d}$ 之后, 独山湖大部分湖区完成更新, 优质水开始进人 南阳湖. 独山湖北岸部分湖区 $\mathrm{NH}_{4}^{+}-\mathrm{N}$ 浓度减小速率低于其他湖区, 仅由 $3.0 \mathrm{mg} / \mathrm{L}$ 下降至 $1.6 \sim 2.5 \mathrm{mg} / \mathrm{L}$. 其他独山湖湖区水体交换较快, $\mathrm{NH}_{4}^{+}-\mathrm{N}$ 浓度最后稳定在 $1.1 \sim 1.2 \mathrm{mg} / \mathrm{L}$; 调水 $160 \mathrm{~d}$ 之后, 南阳湖大部分湖 区完成更新, 最后南阳湖 $\mathrm{NH}_{4}^{+}-\mathrm{N}$ 浓度稳定在 $1.2 \sim 1.3 \mathrm{mg} / \mathrm{L}$. 调水 $270 \mathrm{~d}$ 时, $\mathrm{NH}_{4}^{+}-\mathrm{N}$ 浓度分布见图 $6 \mathrm{c}$.

调水初期出湖 DO 浓度较低, 随着湖水更新和水温降低, DO 浓度开始增加, 到调水后期 ( $200 \mathrm{~d}$ 之后) 因 水温增加, DO 浓度开始降低, 调水结束时在 $5.2 \mathrm{mg} / \mathrm{L}$ 左右. 从调水开始到调水 $120 \mathrm{~d}$ 之间 COD 浓度维持在 $30.0 \mathrm{mg} / \mathrm{L}, 120 \mathrm{~d}$ 之后优质水流人该湖区, 其 COD 浓度开始降低, $160 \mathrm{~d}$ 之后湖水更新结束, COD 最后稳定 在 $23.0 \mathrm{mg} / \mathrm{L}$ 左右. 从调水开始至调水 $120 \mathrm{~d}$ 左右, $\mathrm{NH}_{4}^{+}-\mathrm{N}$ 浓度维持在 $2.3 \mathrm{mg} / \mathrm{L}$, 调水 $160 \mathrm{~d}$ 之后降低到 $1.5 \mathrm{mg} / \mathrm{L}$ 左右并保持稳定. 南四湖出湖各水质指标浓度变化曲线见图 7.

方案二: 同样由于水流作用的降低, 上级湖水体更新完成时间推迟至 $230 \mathrm{~d}$; 由于二级坝人湖水质较方 案一差, 稳定后各湖区 $\mathrm{COD}$ 和 $\mathrm{NH}_{4}^{+}-\mathrm{N}$ 浓度略高于方案一, 分别高 $4.0 \mathrm{mg} / \mathrm{L}$ 和 $0.6 \mathrm{mg} / \mathrm{L}$; 出湖水质较方案一 略差(图 7).

从输水调度过程和水力、水质变化过程看, 影响南四湖水量水质的主要因素有初始水体的水质特性及 纳污能力, 湖区的水力特性及流场分布,水体交换周期及人湖支流水质等.
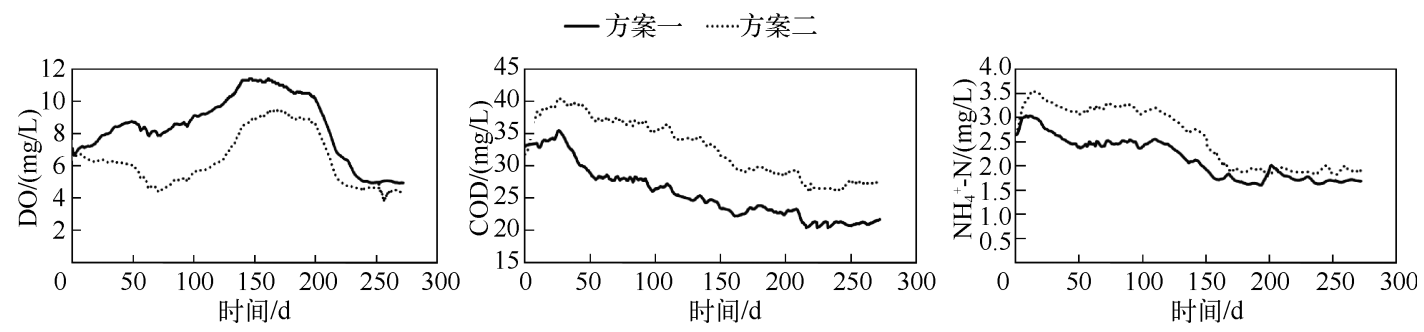

图 7 南四湖出湖水质浓度变化曲线

Fig. 7 Variations of the water quality parameters out of Lake Nansi

\section{4 调度管理建议}

通过模拟计算结果表明, 由于南四湖处于东线苏鲁省际交水地段, 调水期人湖河流污染影响较大, 水系 和管理关系比较复杂, 采取改善水力、水质特性, 缩短水体更新周期等措施, 进一步使南四湖水质改善并保 持稳定.

\section{1 改善水力特性}

由于上级湖人湖河流较多, 通过采取改善南四湖水力特性的措施改善南四湖调水期水质状况. 建议适 当调整进出湖泵站的运行顺序, 先利用二级坝泵站调水人上级湖, 适度超蓄以增加上级湖的总水量, 提高其 纳污能力, 减少或推迟水质相对较差的人湖河流流量. 基于本文建立的南四湖三维水力调配和水质模型, 进 一步细化考虑周边取水口的取水时间和取水量, 以改变进人南四湖的流场分布. 条件具备时, 可以采取疏浚 或拓宽上级湖等工程措施, 改善南四湖上级湖的水力条件.

\section{2 改善水质特性}

南四湖周边污染主要有城镇污染点源、航运及渔业等线源、农业化肥等面源. 通过实施城镇污水处理工 程、截污导流工程、工业结构调整、工业综合治理、流域综合治理和人工湿地水质净化示范工程等措施, 南四 湖水质已取得较大改善. 截止 2009 年底, 江苏省南水北调沿线 14 个控制断面, 12 个已达到地表水 III 类标 准, 达标率为 $85.7 \%$, 较 “十五” 末增长 $21.4 \%$; 山东省 22 个控制断面 $\mathrm{COD}$ 和 $\mathrm{NH}_{4}^{+}-\mathrm{N}$ 平均浓度较 2002 年分 
别下降了 $65.9 \%$ 和 $86.0 \%$. 水质的不断改善, 为南水北调良性运行创造了条件.

计算结果表明, 来水水质的优劣直接决定南四湖出湖的水质状况. 因此, 在保证供水水量的前提下, 可 视运河线 (韩庄㬌站) 和运西线 (萄家坝㬌站) 来水的水质, 加大或减少相应㬌站的抽水水量, 增加优质水的 进出湖速度. 在水源选择上, 可根据长江水 (运河线) 和淮河水 (洪泽湖) 的来水水质, 选择水质较好的水源. 同时, 为保持水质持续稳定和改善, 在南水北调调度管理上, 建议建立水质监测系统预警预报系统, 加强对 重点河段和湖区的监测预报和预警.

\section{3 缩短水体更新周期}

通常, 水体更新周期越长, 可供利用的水资源量就越小; 反之, 可供利用的水资源量就越大 ${ }^{[15]}$. 通过分析 模拟结果, 南水北调东线一期工程正常调水运行 $50 \mathrm{~d}$, 南四湖下级湖水体更新完毕, 水质达标并保持稳定; 调水运行 $160 \mathrm{~d}$, 南四湖上级湖才能完成水体更新. 从时间上看, 南四湖上级湖的更新周期过长, 不利于水质 达标和保持稳定. 因此, 建议尽快实施南水北调东线第二期和第三期工程, 进一步加大人南四湖上级湖的水 量 (从 $19.64 \times 10^{8} \mathrm{~m}^{3}$ 提高到 $66.12 \times 10^{8} \mathrm{~m}^{3}$ ), 缩短水体的更新时间, 使南水北调东线工程尽快投人持续良性 运行.

\section{5 结论}

利用南四湖三维水力调配和水质模型, 模拟南水北调东线一个完整调水期内南四湖常规、干旱调水工 况调度运行过程, 结果表明: (1) 调水过程中, 下级湖和上级湖未出现大范围的环流现象, 湖水流态平稳; (2) 出湖水的 DO、 $\mathrm{COD} 、 \mathrm{NH}_{4}^{+}-\mathrm{N}$ 浓度大部分时间满足 III类水质要求, 流速快的区域水质变化速率较高; (3) 受 地形条件影响, 南四湖上级湖水体交换周期长于下级湖; (4) 人湖支流水质对人湖口附近水质影响较大; (5) 比较常规与干旱调水两种方案, 受水力特性的影响, 后者湖区水体更新时间较长、出水水质略差. 为保证 南四湖水质的持续稳定, 提出改善水质、水力特性,缩短水体更新周期的工程调度措施和建议.

致谢: 本课题得到天津大学超算中心的支持,在此表示感谢.

\section{6 参考文献}

[ 1 ] Ji ZG, Hu GD, Jian S et al. Three-dimensional modeling of hydrodynamic processes in the St. Lucie Estuary. Estuarine Coastal and Shelf Science, 2007,73 : 188-200.

[ 2 ] Chen Z, Gao XP, Wang LY et al. Analysis of agricultural pollution by flood flow impact on water quality in a reservoir using a three-dimensional water quality modeling. Journal of Hydroinformatics, 2012 (doi: 10. 2166/hydro. 2012. 131).

[3] 张 晨, 高学平, 朱慧芳等. 以氯离子为例的北大港水库水质调控技术. 天津大学学报, 2012,45(1):6-12.

[4] 何少苓,彭 静. 论提高水域纳污与自净能力的水动力潜力. 中国水利,2003,(1A):71-73.

[5] 傅 春,林永钦. 长江流域大型湖泊综合承载能力研究. 北京:科学出版社, 2011 .

[6] 赖锡军, 姜加虎, 黄 群等. 鄱阳湖二维水动力和水质耦合数值模拟. 湖泊科学, 2011,23(6):893-902.

[7] 谢兴勇,钱 新, 钱 瑜等. “引江济巢”工程中水动力及水质数值模拟. 中国环境科学, 2008,28(12):1133-1137.

[8] 周小平, 翟淑华, 袁 粒. 2007 2008 年引江济太调水对太湖水质改善效果分析. 水资源保护, 2010,26(1):40-48.

[9] 罗 辉. 南水北调改善南四湖水流水质特性及湖滨带控污技术研究 [ 学位论文]. 南京: 河海大学,2006.

[10] 武周虎, 张晓波, 张芳园. 南四湖人湖重点污染河流笁选与水环境问题分析. 长江流域资源与环境,2011, 20 (4): $475-481$.

[11] Hamrick JM. Users' manual for the environmental fluid dynamics computer code. Spec Rep In Appl Marine Sci and Oc Engi, Virginia Inst of Marine Science, Vas 1996.

[12] Hamrick JM. Three-dimensional variable resolution hydrodynamic and transport modeling of the Chesapeake Bay system. Proceedings National Conference on Hydraulic Engineering, New York: ASCE, 1993, 2 : 2110-2115.

[13] Sen B, Lung WS. Three-dimensional modeling of fecal coliform in the Tidal Basin and Washington Channel. Journal Environ Sci Heal, 2006, 41(7): 1327-1346.

[14] Ji ZG. Hydrodynamics and water quality: modeling rivers, lakes, and Estuaries. New York: A John Wiley \& Sons Inc Publication, 2007.

[15] 刘昌明,蒋晓辉. 基于水库调蓄的黄河干流水体交换周期的量化研究. 地理学报,2004,59(1):111-117. 